\title{
Trying the easiest solution first in other-initiation of repair
}

\author{
Jan Svennevig
}

\begin{abstract}
This article is an empirical investigation of how other-initiations of repair present a diagnosis of the trouble source and how addressees respond to this diagnosis. It is claimed that there is a preference for trying the least serious (complicated, sensitive) solution first, that is, for addressing problems as hearing problems over addressing them as problems of understanding or acceptability. One realization of this preference is that understanding and acceptability problems are often initially addressed as hearing problems, and only subsequently taken up as problems of understanding or acceptance. Another is that addressees of hearing repair initiations occasionally react by anticipating problems of understanding and acceptability and proceeding to repair these problems, for instance by offering explanations or modifications of their original utterance. The preference hierarchy can also explain how interactants deal with what has been up until now considered an especially vague or ambiguous type of repair initiation, namely open class repair initiators (such as "huh?").
\end{abstract}

\section{Introduction}

In initiating repair of an interlocutor's utterance, conversationalists indicate the presence of a problem. But in addition, they may also locate it more precisely in the previous turn, or present a diagnosis of what the source of the problem is, for instance, as hearing or understanding. This is apparent in the following example:

(1) From Schegloff et al., 1977: 369

1 A: I have a: - cousin teaches there.

2 D: Where.

3 A: Uh:, Columbia.

$4 \quad$ D: $->$ Columbia? 
5 A: Uh huh.

$6 \quad$ D: $->$ You mean Manhattan?

7 A: No. Uh big university. Isn't that in Columbia?

$8 \quad$ D: Oh in Columbia.

9 A: Yeah.

The repair initiations in lines 4 and 6 both indicate that there is a problem with the utterance in line 3. However, they present a different diagnosis of the problem. The repeat construes it as a problem identifying what was said and suggests a remedy by presenting a candidate hearing. The second initiation presents a candidate correction and thus construes the problem as a potential "misspeaking" by the interlocutor. Clearly, these two construals of what the problem consists in are not equal as to their social implications. The first places the responsibility for the problem on the repair initiator himself, not having heard what the other said, whereas the second places the "blame" on the interlocutor (cf. Robinson, 2006). The repair initiator thus tries the most "innocuous" solution first, and only when this fails to solve the problem, tries the more socially sensitive solution.

This strategy of trying the "least complicated and costly remedy" first has been described by Pomerantz (1984). In this article, I investigate whether this is a general preference in the choice of repair initiation techniques and which patterns of initiation follow from it. The questions I aim to answer are:

1) Is there a preference for addressing problems in conversation as a hearing problem over addressing them as problems of understanding or acceptability?

2) Is there a systematic relation between the format of other-initiation and the nature of the problem as displayed in the repair proper (as resulting from problems of hearing, understanding or accepting the prior turn)?

\section{Previous studies of ordering of repair initiators}

In a footnote to their paper on repair, Schegloff, Jefferson and Sacks (1977) claim that there is a "natural ordering" of other-initiations of repair. This order is "based on their 
relative "strength" or "power" on such parameters as their capacity to "locate a repairable" (p. 369). Schegloff has later specified the claim further:

The least specific take the form of queries such as "Huh?" or "What?" or "Pardon me"; they increase in specificity (or power to locate the trouble) when made category-specific ("Who?", "Where?", etc.), or by repeating the target repairable, and most specific of all when offering for confirmation some formulation of the hearing or understanding which the trouble-source produced. (Schegloff, 2007:101)

In this context, then, "strong" and "weak" initiators constitute a scale of specificity in identifying the trouble source. Schegloff et al. (ibid.) go on to claim that there is a preference for stronger over weaker initiators. The empirical basis for this claim is that "if more than one other-initiated sequence is needed, the other-initiators are used in order of increasing strength" (p. 369). Example (1) above is given as evidence for this claim. The first initiation is a category specific initiator and the second is a stronger initiator in that it offers a formulation of the repair initiator's understanding.

A couple of studies have offered empirical support for this claim. Mazeland (1987) has described initiation techniques in practices of repair of errors in school lessons. He finds the following formats:

Error-indication: indicate the occurrence of an error in prior turn, e.g. "there's a mistake"

Error-location: locate the error more precisely within prior turn, e.g. "you said (0.5) in the Oxfordstreet"

Error-method: analyze the sources of the error, e.g. "you are mixing it up now." Repair-method: instruct the pupil how to make the correction, e.g. "[...] you just have to (0.4) partitionate [sic] them in (0.8) eighteenth"

Mazeland notes that the techniques are ordered in line with the ranking described by Schegloff et al. (1977), so that in sequences of several initiations the first "weak" ones come before "stronger" ones.

Clark \& Schaefer (1987) have studied the ordering of responses to information given in directory enquiries to a telephone company. The requested information was 
numbers and names, so the issue of concern was hearing and not understanding. They find the following ordering of responses to the information presented, in ascending order of strength, defined as power to ground the information presented:

(a) Assert no hearing (“I didn't hear you”)

(b) Presuppose no hearing ("What?")

(c) Presuppose incomplete hearing (“12?”, "Ross what?”)

(d) Presuppose fallible hearing (“12345?”, Ross and fox?”)

(e) Display full hearing (“12345”, "Ross and fox")

(f) Assert full hearing ("Right")

(g) Presuppose full hearing ("Thank you”)

The ordering of initiators is manifested in that they find sequences of responses displaying increasing strength, for instance $\mathrm{e}+\mathrm{f}+\mathrm{g}$ or $\mathrm{e}+\mathrm{g}$, but not the inverse.

In addition to these studies of problem specification, we also find studies of ordering of initiation formats according to various sorts of trouble sources. Already Harvey Sacks noted that admitting a failure to understand may display a lack of competence of some sort (vocabulary, encyclopedic knowledge etc.), and thus be done less willingly than asserting that one did not hear (Sacks, 1992, vol. 2:413). And Pomerantz (1984) shows that different types of problems may be to a larger or lesser extent serious to the interactants and their relationship. Her case analysis involves a potential disagreement that is initially treated as a problem of reference. Clarifying a referring expression, she notes, is less complicated than addressing a potential disagreement in three ways: the problem is more easily detectable, it is sequentially quicker to resolve, and it is socially less complicated, not being taken as reflections of character or relationship deficiencies. Interactants will therefore in general "try the least complicated and costly remedy first" (Pomerantz, 1984:156).

Also Schegloff (2007) has described a tendency to address problems of alignment by introducing repair of hearing or understanding. He writes:

A variety of features of other-initiated repair sequences make them apt and suitable instruments for addressing disagreement-implicated talk. For example, by not quite "getting" what was said, they raise the possibility that it was "not quite right," often leaving the respects in which it was not quite right 
unexplicated. More to the point for the actual working out of the "problem," they provide a place in the very next turn in which the prior speaker can make some adjustment in what was said - to make it more accessible, and perhaps more “acceptable.” (Schegloff, 2007:151)

There are some studies pointing to such an ordering of repairables in various contexts. Selting $(1987,1988)$ has identified a preference hierarchy in German conversation in which manifestations of "local understanding problems" are preferred to manifestations of "global" ones. And within the category of local problems acoustic problems are preferred to semantic problems (reference assignment and meaning ascription), which in turn are preferred to problems of expectation.

Mazeland \& Zaman-Zadeh (2004) have studied other-initiated wordclarification repair in lingua franca interactions. In their data, almost all cases of other-initiated word-clarification repair occur after an initial attempt at hearing repair has been unsuccessful. This leads them to state a rule of "non-firstness" of wordclarification. Also Sorjonen's (1996) study of repeats and responses in Finnish conversation reports on a common pattern in which requests for clarification and disaligning actions are preceded by repeats + confirmation.

As we see, several studies indicate that there is an ordering of other-initiation techniques along at least two different scales. Some address different degrees of specificity in locating the problem, like Schegloff et al (1977), Clark \& Schaefer (1987) and Mazeland (1987), whereas others seem to invoke an ordering between repair of hearing, repair of understanding and disagreement, such as Pomerantz (1984), Schegloff (2007), Sorjonen (1996) and Mazeland \& Zaman-Zadeh (2004). In the following, I will concentrate on the latter hierarchy, and investigate whether there is a general preference for treating problems as hearing problems over understanding or acceptability problems. But first I will present a framework for describing how these hierarchies are manifested in conversation.

\section{Types of trouble sources and techniques for addressing them}

Schegloff et al. (1977) define repair as dealing with "recurrent problems in speaking, hearing, and understanding." Other-initiation of repair thus involves displaying a 
problem in one of these domains and possibly also requesting information that will remedy it. However, to my mind the formulation "problems of speaking" evokes a too narrow conception of the nature of the problems, namely as being just a matter of "misspeaking". But the problems may concern many aspects of producing an utterance that is recognized as a valid or felicitous social action in a given situation. In addition to linguistic problems (pronunciation, vocabulary, syntax etc.) it also includes acceptability problems, such as saying something "wrong" in a wide sense, that is, untrue, inappropriate, irrelevant etc. (cf. Schegloff (2007), cited above). In the following I will speak of problems of acceptability for these sorts of problems rather than "problems of speaking".

The differences in social implications and cognitive work involved in addressing the different kinds of trouble calls for an analytical division between types of trouble source and methods for dealing with them. In the following, forms of otherinitiated repair will be differentiated according to whether the source of the problem is hearing, understanding or acceptability. In addition, I will distinguish between 3 methods of presenting the problem, ranging from the weakest to the strongest form of repair initiation. First, speakers may merely indicate the presence of a problem; second, they may specify what the problem is, and third, they may suggest a candidate solution to the problem.

Problems of hearing. "Hearing an utterance" amounts to coming to a construal of the linguistic form of the utterance, that is, its lexical, syntactic and prosodic features. Indicating a problem of hearing may be done explicitly ("what did you say?”) or implicitly (“huh?”, "pardon?” etc.). Problem indications may be unspecific, as in these cases, or specific, as in partial repeats plus a question word ("Ross what?"). Repair initiations may merely indicate a problem, as in the prior cases, or they may suggest a solution to it, for instance by presenting a potential hearing of the prior utterance (as in (1) above: “Columbia?").

Problems of understanding. This involves coming to a construal of such things as the action being performed by the utterance, the referents being invoked by the referring expressions, and the implicatures being conveyed by the wording. Problems of understanding may be indicated by displays of incomprehension, such as for instance "what do you mean?" The nature of the problem may furthermore be specified by using clarification requests. For instance in (1) above, D initiates repair by asking for clarification ("where", 1. 2), thereby signaling a problem of identifying 
the referent of the referring expression in the prior turn ("I have a: - cousin teaches there."). Finally, the problem may be attempted to be solved by presenting a candidate understanding of the prior utterance in a so-called understanding check. This may e.g. be realized by the phrase "you mean" + a paraphrase.

Problems of acceptability. Previous research has recurrently addressed the phenomenon of "error correction" (cf. Jefferson, 1975, Mazeland, 1987 etc.) but problems of acceptability extend well beyond this. They concern the acceptability of the contribution not just as a linguistic utterance, but also as a social action. To accept a conversational action can involve such different things as the truth of the claims made, the speaker's right to perform the action in question, the relevance of the utterance to the current situation, etc. As noted by Mazeland (cited above), speakers may merely indicate the presence of a problem: "there's a mistake". Specifying the nature of the problem may take the following form: "you said (0.5) in the Oxfordstreet". Proposing a solution may be done by proposing a candidate correction, as in: "You mean Manhattan?" in (1) above. ${ }^{1}$

This description of repair initiation formats leads to a two-way classification according to source of trouble and method of problem management. This can be illustrated as in table 1 .

\begin{tabular}{|l|l|l|l|}
\hline & Hearing & Understanding & Acceptability \\
\hline $\begin{array}{l}\text { Unspecific } \\
\text { problem indicators }\end{array}$ & $\begin{array}{l}\text { Display of non-hearing: } \\
\text { "Huh?" "What did you } \\
\text { say?" }\end{array}$ & $\begin{array}{l}\text { Display of incompre- } \\
\text { hension: "What do you } \\
\text { mean?" }\end{array}$ & $\begin{array}{l}\text { Error indication: } \\
\text { "There's a } \\
\text { mistake" }\end{array}$ \\
\hline $\begin{array}{l}\text { Category specific } \\
\text { indicators }\end{array}$ & $\begin{array}{l}\text { Repeat with question } \\
\text { word: "Ross what?" }\end{array}$ & $\begin{array}{l}\text { Clarification request: } \\
\text { "where?" }\end{array}$ & $\begin{array}{l}\text { Error specification: } \\
\text { "you said (0.5) in } \\
\text { the Oxfordstreet" }\end{array}$ \\
\hline $\begin{array}{l}\text { Candidate } \\
\text { solutions }\end{array}$ & $\begin{array}{l}\text { Hearing check } \\
\text { (full/partial repeat): } \\
\text { "Ross and fox?" }\end{array}$ & $\begin{array}{l}\text { Understanding check: } \\
\text { "you mean" + } \\
\text { paraphrase }\end{array}$ & $\begin{array}{l}\text { Candidate } \\
\text { correction: "you } \\
\text { mean" + correction }\end{array}$ \\
\hline
\end{tabular}

Table 1: The relation between sources of trouble and formats of other-initiated repair

\footnotetext{
${ }^{1}$ As a note of caution it is important to stress that as conversation analysts we don't have access to the actual causes of communication problems. What is of interest here is rather what is presented as the nature of the problem, which may in actual fact, be correct or incorrect, sincere or insincere, naively or strategically chosen.
} 


\section{Distribution}

The data for the study is drawn from two sources: a corpus of informal conversation between unacquainted interlocutors (cf. Svennevig, 1999) and a corpus of institutional interaction, namely consultations in various social welfare offices between native Norwegian social workers and non-native clients (cf. Svennevig, 2003). The data corpora are rather dissimilar as to type of situation, and I do not intend to go into detail about the specific characteristics of each data set. My intention is to describe general principles of repair initiation that cut across different situations and activities. For this purpose the variation represented by the data sets is an advantage, since it shows that the principles identified are common to very different conversational activities. There are certain differences in the distribution of repair initiation formats in the two corpora, but they constitute differences of degree and not of principle, so that no repair formats were found exclusively in one data set.

A collection of 285 other-initiations of repair were excerpted and analyzed individually in order to find out what source of trouble was indicated by the repair initiation, that is, hearing, understanding or acceptability, and how specific it was in indicating the nature of the trouble, namely unspecific problem indicators, category specific indicators, candidate solutions. The distribution of the excerpts is presented in table 2.

\begin{tabular}{|lcccc|}
\hline & Hearing & Understanding & Acceptability & Total \\
\hline Unspecific problem indicators & 21 & 9 & 0 & 30 \\
Category specific indicators & 3 & 21 & 50 & 74 \\
Candidate solutions & 71 & 99 & 11 & 181 \\
Total & 95 & 129 & 61 & 285 \\
\hline
\end{tabular}

Table 2: The distribution of other-initiations of repair on various sources of trouble and various degrees of specificity in diagnosing the problem.

From table 2 it seems clear that in repairing hearing and understanding there is a rather strong tendency towards presenting candidate solutions to the problem (checking hearing and understanding) over merely indicating the presence of a 
problem or specifying the nature of it. For hearing repair candidate solutions are presented in 71 instances, whereas unspecific and specific problem indicators amount to 24 instances taken together. For understanding repair candidate solutions represent 99 instances as compared to 30 problem indicators. Candidate solutions are thus more than three times as common in the data as the two first methods taken together. However, when it comes to acceptability, the pattern is inversed; there are 50 problem indicators and only 11 candidate solutions. From just looking at general frequency we thus get the impression that speakers are biased towards presenting solutions in dealing with problems of hearing and understanding and towards merely indicating the nature of the problem when dealing with problems of acceptability. One reason for this difference between types of trouble sources may be that they place the responsibility for the problem differently (cf. Robinson, 2006). Hearing and understanding repair initiators may be considered as placing the responsibility on the repair initiator (by admitting a failure to hear or understand), whereas acceptability repair initiators place it on the speaker of the trouble source turn (by implying that s/he has said something wrong or inappropriate). Presenting a candidate solution to an acceptability problem thus exposes the potential inadequacy of the interlocutor in a way that candidate solutions to hearing or understanding problems do not.

The unequal distribution of strong and weak initiators may indicate that the types of trouble source are not equal and are ordered in a preference hierarchy of their own. Furthermore, we may observe that the different types of trouble source are not equally common. Acceptability repair is the least common repair type in the data, with 65 instances, compared to hearing repair, with 95 instances, and understanding repair with 129. In addition, some initiation types are especially rare, namely candidate corrections and unspecific displays of incomprehension ("what do you mean?"). This calls for a closer examination of the characteristics of acceptability repair initiation in relation to the initiation of hearing and understanding repair, which is the topic of the next section.

\section{A preference for the least serious construal of problems}

In the following, I will investigate whether there is a separate preference hierarchy between initiators that construe the problem as involving hearing, understanding or 
acceptability. The preference oriented to by the participants can be formulated as follows:

\section{A preference for the least serious construal of problems}

In the choice between different ways of addressing a problem in conversation, construing it as a hearing problem is preferred to construing it as an understanding problem, which in turn is preferred to construing it as an acceptability problem.

The evidence for this preference is to be found, first, in the directionality of multiple repair initiations, second, in methods for pre-empting serious problems after hearing repair initiators and, third, in the scarcity of understanding and acceptability repair in first initiations of repair. I will go through the pieces of evidence in turn.

Many of the examples of multiple repairs in the data involve a progression from hearing repair to repair of understanding or acceptability. Here is an instance, where the speaker first tries a hearing check and then goes on to an understanding check:

(2) Institutional interaction: $\mathrm{C}=\mathrm{Client}$ (non-native speaker), $\mathrm{S}=$ Social worker (native)

1 C: $\quad$ Men (.) h er det bek- be- eh:: b- bakerjobb er det $\uparrow \underline{\text { bra }}$ eller $\downarrow$ nei?

$2 \quad$ But (.) is it bek- be- uh: b-bakerjob is that good or no?

3 S: Bakerjobb?

5 C: $\quad$ Ja

$6 \quad$ Yeah

S: .hh Ja bake brød er det det du mener eller? Well bake bread is that what you mean? (Yes bake bread is it that you mean or)

C: mh: baker i: den ligger på Hasle og den ( ) mh baker in it's at Hasle and it ( )

The two repair initiations in line 3 and 8 seem to be equally specific in locating the repairable, namely in the expression "bakerjob". However, they locate it in different 
domains: The first treats it as a hearing problem and suggests a solution by presenting a candidate hearing, whereas the second treats it as a problem of understanding and suggests a solution by presenting a candidate understanding. That the first diagnosis of the problem is preferred to the other is evidenced by the fact that it is presented immediately and without delay, whereas the second is presented only after the first has failed and after an extended pause of 3.2 seconds. $^{2}$

The same pattern is observable when it comes to acceptability. Here is an example of an answer that is not accepted as appropriate in the given institutional context:

(3) Institutional interaction: $\mathrm{C}=\mathrm{Client}$ (non-native speaker), $\mathrm{S}=$ Social worker (native)

\footnotetext{
${ }^{2}$ This silence gives the speaker of the trouble source the opportunity of taking the turn to rephrase or elaborate on the question. The fact that the recipient (S) lets the pause grow so long increases the relevance of such an intervention. However, the opportunity is not seized.
} 
$1 \quad$ S: Kan du fortelle litt om hva du (.) har gjort etter at du kom til Norge?

$2 \quad$ Can you tell me a bit about what you have done after you came to Norway?

3 C: Ingenting.

$4 \quad$ Nothing.

5 S: Ingenting?

$6 \quad$ Nothing?

7 C: Ja ha ha ha [ha ha]

$8 \quad$ Yeah

$9 \mathrm{~S}$

[ha ha] ha

C: m:hm:,

13 S: Du må vel ha gjort noe?

You must have done something?

C: ha ha ha

S: Hæ?

Huh?

C: .hhh

S: Har du gått på no norsk-kurs?

Have you attended any Norwegian courses?

C: $\quad$ eh ja

uh yes

The repeat in line 5 presents a candidate hearing of the answer and gets responded to in line 7 with a minimal confirmation followed by laughter (which is subsequently reciprocated by the social worker). However, the following two questions (1.10 and 13) display a problem beyond the identification of linguistic form. They are both new repair initiations that address the acceptability of her answer ("nothing"), questioning its correctness or appropriateness. However, these questions do not give any hints about what sort of answers would be appropriate, and the client fails to provide a new and acceptable answer. In line 19, the social worker changes the line of questioning altogether, and instead starts to enquire about her participation in specific activities. Again the pattern is that the problem is first treated as a hearing problem by merely repeating the problematic utterance. Only when this initiation does not yield a 
solution, does the initiator go on with repair that addresses problems in other domains. The socially more sensitive diagnosis, indicating that the answer is not appropriate, is tried only as a second solution.

Treating the problem as a hearing problem may thus seek to avoid raising sensitive issues. In the next example this involves displaying a lack of encyclopedic knowledge:

(4) Unacquainted interlocutors: $M=$ Marta, $S=$ Sven

1 S: Det var en kompis av meg som fikk sånn: jobb han skulle utbedre: There was this friend of mine who got like a job he was supposed to improve

3 > Han er sånn automasjonsingeniør da. $<$

$4 \quad$ He is an automation engineer you see.

(.)

$6 \quad$ S: Så han [fikk jobb med]

So he got a job with

\section{M: [ A u t o : ]mosjon?}

Automotion?

S: Automasjon.

11 Automation.

12 M: Åh?=

13 Oh?

14 S: =Sånn som automatisere bedrifta [og sånn.]

15 Someone who automatizes companies and things.

$16 \mathrm{M}$ :

[ J a : ] akkurat.

Yeah right.

18 S: [Og han::] fikk jobb på den kornsiloen for å:: gjøre om dataanlegget demmers, 19 And he:: got a job in that grain silo to: modify their computer system,

20 M: [ j a ? ]

Marta first tries a hearing check (1. 8), but after her construal of linguistic form has been checked and corrected (from "automotion" to "automation") she continues to display incomprehension by means of the questioning particle “Åh?” (“Oh?”) in line 
12. ${ }^{3}$ This involves displaying that she does not know a word that Sven had taken for granted that she knew, and this may potentially constitute a more delicate matter.

It is thus a common pattern in the data that problems of understanding or acceptability are at first addressed as hearing problems. When identification of the linguistic form does not solve the problem the repair initiator makes a new attempt, this time addressed to a problem in a different domain.

A second type of evidence for the preference for the least serious construal of the problem is that hearing repair initiations sometimes give rise to anticipation and preemption of other problems by the interlocutor. Hearing repair initiations may alert the interlocutor to the fact that there might be a problem in another domain and initiate pre-emptive techniques to address this problem. Consider the following example:

(5) Unacquainted interlocutors: V=Victoria, $\mathrm{R}=$ Ragnhild

\footnotetext{
${ }^{3}$ This particle has not been described systematically in Norwegian, but my own inspection of several corpora of conversational language indicates that it seems to be used as a display of incomprehension or surprise.
} 
1 R: For jeg tenkte på det atte:: at jeg lurte på om du hadde kalt Cause I was thinking that: that I was wondering whether you had called deg Victoria etter at Victoria Matt ble kjent? yourself Victoria after Victoria Matt got famous?

6 R: [fo- $]$

$\mathrm{V}: \quad$ [Etter] at Vic [toria?]

$\mathrm{R}:$

After Victoria?

\section{vet du hvem det er?}

do you know who that is?
$\mathrm{R}:$
No (emphatic)
$\mathrm{V}: \quad$ Næ⿱⺈⿻日乚㇒i. [
( ( $1 \mathrm{a} \mathrm{u} \mathrm{g} \mathrm{h} \mathrm{s} \mathrm{)} \mathrm{)}$
R: [Nei. ((laughs)) Hun er skuespiller,]
No She's an actress,

The request for repetition of a specific constituent in line 7 is immediately granted, but Ragnhild seems to anticipate a problem at the level of reference, namely that Victoria does not know who Victoria Matt is. This piece of background knowledge was presupposed in Ragnhild's original utterance. She thus asks her whether she knows the person (1.11) and thereby initiates a side sequence to adjust this asymmetry of knowledge. ${ }^{4}$ The excerpt thus shows that a request for repetition of a name - a hearing repair initiator - gives rise to an anticipation of a problem of reference - an understanding problem - which is then addressed by checking the interlocutor's background knowledge.

In other cases speakers may be seen to anticipate a problem of understanding or acceptability in that they go directly on to repairing this problem instead of offering repair of hearing. This is the case in the following example, where a social worker is inquiring about where the client's children are in the daytime:

(6) Institutional interaction: $\mathrm{C}=\mathrm{Client}$ (non-native speaker), $\mathrm{S}=$ Social worker (native)

\footnotetext{
4 This type of side sequence checking background knowledge related to the current topic has been described more in detail in Svennevig, 1999:284.
} 
1 S: Hvor er de om dagen a,

2 So where are they during the day,

$3 \quad$ Er de i (ei) barnehage eller?

$4 \quad$ Are they in day care?

5 C: Eh to barna går barnehagen,

6 Two children go to day care

$7 \quad \mathrm{~S}: \quad[\mathrm{Ja}]$

$8 \quad$ Yes

9 C: [Jen]ta min er på sykehus. he he [ he he he ] he

10 My girl is in the hospital.

11 S:

12

13 C: Hun er syk.

14

15

16

17

18

\section{[På sykehus?]}

In the hospital?

The client's answer that one of her children is not in daycare but in a hospital (1. 9) is responded to by a questioning repeat: "In the hospital?" (1. 11). Although this repair initiation is designed to elicit a confirmation, the client does not produce a type conforming response (cf. Raymond 2003), but instead elaborates by giving an explanation ("she's ill", 1. 13). She seems to anticipate that the social worker has a problem of understanding and goes on to repair that problem rather than just confirming his construal of her utterance.

Also problems of acceptability may be anticipated from an initiation of hearing repair and thus addressed in the repair proper. Here Hilde and Jens are talking about their fellow students' lack of involvement in their studies. Hilde suggests that the involvement grows as the students advance in their studies, and this leads to a discussion about the various levels of their degree (translated as "first" and "second year"):

(7) Unacquainted interlocutors: $\mathrm{H}=$ Hilde, J=Jens 
$1 \quad$ H: (.) Men det kommer etter hvert asså.

But it comes after a while.

(.).

Det gjør jo det, sånn som nu, (.) [ det e klart nu ] It does you know, like now, obviously now

$6 \mathrm{~J}:$
[Ja vi har jo vært på] grunnfagsnivå.

Yeah we have been in the first year

\section{(.)}

$\mathrm{H}: \quad$ Hva?=

What?

$\mathrm{J}: \quad=$ Ja: det vil si du har jo mellomfag da.

Yeah that is, you are in your second year

(.)

$\mathrm{J}: \quad \mathrm{I}:$ : engelsk.

In:: english

J: $\quad$ Men eh (.) hh når jeg har tatt grunnfag så har jeg: (.) [møter jeg mye:] But eh (.) when I have attended the first year I have (.) I meet a lot

Hilde's problem indicator in line 9 ("what?") is not responded to by repetition; instead, Jens produces a correction of his prior claim. Then he goes on producing a revised version of the original utterance, this time speaking only for himself ("when I have attended...", 1. 16). This can be seen as backing down from his original position in anticipation of an objection from $\mathrm{H}^{5}$ He thus treats Hilde's repair initiation as adumbrating a more serious problem with his utterance, namely a problem of acceptability (the truth of the presupposition that they have both been at the first year) and proceeds to address this problem.

These examples provide several types of evidence that hearing repair is preferred to repair of understanding or acceptability. First, the latter are frequently "delayed" in the sequence of turns by coming after attempts at hearing repair. They are also frequently delayed in the turn itself by pauses and hesitation, as in example (2).

\footnotetext{
${ }^{5}$ In other cases, anticipating an objection may of course engender the opposite reaction, namely an attempt to strengthen one's claim (by providing reasons etc.).
} 
The fact that hearing checks and unspecific problem indicators are responded to by repair of understanding or acceptability does not mean that they themselves signal an understanding or acceptability problem. If the preference for hearing repair is a common resource for interactants one might expect interlocutors to treat hearing repair initiations as potential prefaces to repair initiations in other domains, and thus to inspect their own prior utterance for other potential trouble sources. If they detect a potential problem of understanding or acceptability, they have the opportunity to make a "short cut" by pre-empting a second repair initiation and instead check potential trouble sources or offer self-repair addressing the problem:

\section{Full two-cycle repair sequence:}

Trouble source turn:

B: Bakerjob is that good or no?

Hearing repair initiation (hearing check)

A: Bakerjob?

Hearing repair (confirmation)

B: Yeah

Understanding repair initiation

A: Yeah bake bread, is that what you mean?

Understanding repair

B: Mh: baker in: it's at Hasle.

\section{Background check:}

Trouble source turn:

B: After Victoria Matt got famous

Hearing repair initiation

A: After Victoria?

Hearing repair

B: Victoria Matt,

Background check

Do you know who that is?

Negative response

A: No

Background update:

B: She's an actress

\section{Short-cut repair sequence:}

Trouble source turn:

B: My girl is in the hospital.

Hearing repair initiation (hearing check)

A: In the hospital?

Understanding repair

B: She's ill.

The background check preempts the potentially upcoming understanding repair initiation by checking the existence of a possible trouble source and then offering background information rather than letting the interlocutor have to ask for it. In the 
"short cut repair sequence" the potential problem of understanding is addressed directly after the hearing repair initiation and the understanding repair is thereby embedded in the hearing repair. In this way the actual nature of the problem is not exposed.

The occurrence of "short cuts" seems to indicate an opposite orientation for the producer of the repair, that is, to treat the problem as potentially more serious than indicated. If a hearing repair initiation can be seen as adumbrating an understanding or acceptability problem, the possible lines of action will be one of the following:

1 offer self-repair to preempt that problem (as in (6) and (7))

2 check for the occurrence of a problem (as in (5))

3 not address the problem and let the interlocutor initiate another round of repair if necessary (as in (2)-(4)).

The claim here is thus that these options are ordered from most to least preferred. ${ }^{6}$ This procedure is thus in line with a more general preference for preventing problems over repairing them (cf. Clark, 1994).

The third type of evidence for the preference for the least serious construal of the problem is to be found in the low frequency of direct initiations of understanding and acceptability repair. The pattern of approaching problems of understanding and acceptability only after having tried hearing repair first is very common in the data. As can be seen in table 3, of all requests for explanation (30 in all) 20 are initially addressed as a hearing problem and only 10 are introduced immediately as an understanding problem. Of the 11 candidate corrections in the data, 5 are first addressed as a problem of hearing whereas 6 are produced immediately. In addition, 18 initiations of hearing repair are responded to with "short cuts" to repair of understanding or acceptability. This means that 43 instances $(25+18)$ of understanding or acceptability repair are introduced as hearing problems, whereas only 16 are presented directly as cases of incomprehension or unacceptability.

\footnotetext{
${ }^{6}$ This account of repair organization mirrors Levinson's (1983:356) account of indirect requests in terms of pre-requests being responded to by an offer or a response to the non-overt, projected request.
} 


\begin{tabular}{|lccc|}
\hline Addressed directly & $\begin{array}{c}\text { Preceded by } \\
\text { hearing repair } \\
\text { ("two step repair") }\end{array}$ & $\begin{array}{c}\text { Introduced as } \\
\text { hearing repair } \\
\text { ("short cuts") }\end{array}$ \\
\hline Understanding & 10 & 20 & 17 \\
Acceptability & 6 & 5 & 1 \\
Total & 16 & 25 & 18 \\
\hline
\end{tabular}

Table 3 Number of understanding and acceptability problems addressed as hearing problems vs. addressed directly by displays of incomprehension or unacceptability

The preference for hearing repair seems motivated by concerns of both progressivity (Schegloff 1979, Stivers \& Robinson 2006) and face work (Goffman 1967, Brown \& Levinson 1987, Lerner 1996). Clearly, problems of hearing are in general cognitively easier to resolve than problems of understanding. Identifying linguistic form is primarily a question of mapping between the actual production and the linguistic category system, whereas understanding involves contextually richer forms of reasoning. Furthermore, the solution to a hearing problem may be a simple repeat by the speaker or the addressee. An orientation to progressivity also seems to promote presenting a potential solution over merely indicating the presence of a problem, and specifying the nature of the problem over unspecific problem indicators.

However, as we have seen, strong initiators are not always preferred, and the explanation must be found in face concerns. Even though it might be more efficient to correct an interlocutor than merely to indicate the possibility of an acceptability problem, speakers avoid doing it and perform it in a dispreferred format when they do. Correcting someone else is displaying a deficiency in their contribution and thus constitutes a face-threatening act.

The other form of initiation that is shown to be avoided and produced in dispreferred format is unspecific indications of incomprehension ("what do you mean?”). These repair initiators seem to be dispreferred for reasons both of progressivity and of face work. They do not contribute much to solving the problem (by either specifying the nature of it or by proposing a solution) and they display a potential lack of competence in the speaker. This is thus a matter of saving one's own face rather than saving that of the interlocutor. 


\section{The meaning of open class repair initiators}

This analysis of repair initiation related to types of problems may contribute to explicating the relationship between trouble source and repair initiation format. Certain initiation types have been noted to be used in connection with several different types of repair, especially open class repair initiators (Drew, 1997). An analysis in terms of the current preference hierarchy may explain this multifunctionality.

Drew (1997) has shown that open class repair initiators, in addition to signaling hearing problems, are used to address two kinds of sequential problems, one in which the repairable turn does not connect referentially with its prior turn, and another in which it is somehow inapposite or inappropriate as a response to that prior turn. He concludes that these initiators may be used for a large variety of problems and consequently that "there is no single, determinate relationship between a particular source or kind of trouble, and this (or any other) form of repair initiation" (p. 96). ${ }^{7}$ This multifunctionality has lead to what Sidnell (2006) calls "the otherinitiated repair problem":

"how is the speaker of the trouble source able to determine what kind of problem (hearing, problematic formulation, recognition) a given open class repair initiator is meant to target and, relatedly, what kind of repair (repeats, reformulation, alternate word) will fix the problem" (p. 16).

The current study can contribute to explaining how interactants deal with this apparent vagueness or ambiguity. It shows that the canonical use of open class repair initiators is with problems of hearing. The uses in cases of understanding and acceptability problems, such as the ones described by Drew, may be considered as derived from this practice by the mechanisms associated with the preference for trying the least serious construal first. On this analysis, the initiation treats the problem as a hearing problem, as a first and least costly solution. The fact that the repair proper addresses questions of sequential coherence or appropriateness may be explained as a

\footnotetext{
${ }^{7}$ Also Schegloff (1987) has emphasized the independence of the system of repair organization vis-à-vis the nature of the problems or errors being dealt with in repair.
} 
sequential "short cut", based on the preemption by the interlocutor of a more serious problem.

In this sense, open class initiators are not as vague or ambiguous after all. They seem equivalent to explicit indicators of insufficient hearing, such as "what did you say?" ("hva sa du?"). They get the same types of responses, that is, most often a repeat, but occasionally repairs that pre-empt understanding or acceptability problems. The very fact that they signal insufficient hearing is the reason why they are useful as part of a systematic procedure for addressing delicate problems in a way that avoids bringing the sensitive issue to the surface. However, these initiators do provide for the possibility that hearing repair will solve the problem. And a simple repeat may sometimes be helpful, if only by giving the hearer extra time for working out the repairable's meaning (cf. Drew, 1997:96).

In sum, the fact that participants sometimes respond to open class repair initiators by understanding repair or by preempting a disaligning response does not mean that the initiators themselves signal an understanding or acceptability problem. Open class repair initiators display a construal of the problem as residing in inadequate hearing and typically lead to repeats of the trouble source turn. That they are occasionally responded to by other forms of repair (reformulation, explanation) is a contingent result based on the repair producer's preemption of additional problems.

\section{Conclusion}

The analysis shows that there is a preference for trying the least serious construal of a problem first, that is, presenting a diagnosis of the trouble source as being hearing rather than understanding or acceptability. Frequently, what turns out to be a problem of understanding or acceptability is initially addressed as a hearing problem. ${ }^{8}$

Addressing an understanding or acceptability problem as a hearing problem may have several advantages for the participants. First, it gives the repair initiator more time for working out the meaning and import of the original utterance, and a simple repeat of the target utterance may sometimes be sufficient to continue the conversation. It also

\footnotetext{
${ }^{8}$ However, this tendency is not strong enough to be labeled a "rule of non-firstness", as suggested by Mazeland \& Zaman-Zadeh (2004). Sometimes, understanding and acceptability problems are indeed addressed in the first initiation.
} 
provides for a new opportunity to initiate a second round of repair after the hearing repair slot. In this sense, hearing repair may work as a "placeholder", temporarily suspending the progression of the conversation while the repair initiator considers whether repair of understanding or acceptability needs to be initiated.

The second advantage of starting by hearing repair is the possibility it gives the receiver of the repair initiation to pre-empt a problem of understanding or acceptability and deal with it in the repair proper. First, the speakers may check the comprehensibility and acceptability of the original utterance. Another option is to address a potential problem of understanding and offer an explanation. In cases of potential problems of acceptability, the original speakers may modify their utterance in order to make it more acceptable to the interlocutor, for instance by correcting an error or by backing down from a potentially controversial position. In this way, the preference organization of initiation types displays a fundamental orientation to face, allowing participants to handle potentially delicate problems in ways that do not expose their face-threatening aspects.

In spite of many declarations that repair organization is not dependent on the nature of the problem, there does seem to be certain prototypical connections between repair initiation formats and sources of trouble. More specifically, open class repair initiators do not seem to be general purpose repair initiators, but are shown to signal a hearing problem. They work in an identical way and occur in identical surroundings as corresponding explicit requests for hearing repair, such as "what did you say?" ("hva sa du"). The fact that they are sometimes used with other types of problems is explained by the preference for hearing repair, which treats the problem as a hearing problem even though it may turn out to be something else. This preference operates equally on open class repair initiators as on other hearing repair initiators.

The current study substantiates Pomerantz's (1984) claim that speakers “try the least complicated and costly remedy first". It describes a practice that allows conversationalists to preempt problems and avoid certain forms of repair. In this way, it may open the way to further investigation of not just how people remedy existing problems but also practices for anticipating problems and preventing them from arising.

\section{References}


Brown, Penelope \& Levinson, Stephen C., 1987 Politeness: Some Universals in Language Usage. Cambridge: Cambridge University Press.

Clark, Herbert H., 1994. Managing problems in speaking. Speech Communication 15, 243-250.

Clark, Herbert H. and Schaefer, Edward F., 1987. Collaborating on contributions to conversations. Language and Cognitive Processes 2, 19-41.

Drew, Paul, 1997. "Open” class repair initiators in response to sequential sources of troubles in conversation. Journal of Pragmatics 28, 69-101.

Goffman, Erving, 1967. On face-work. In: Goffman, Erving, Interaction Ritual: Essays on Face-to-Face Behavior. New York: Pantheon, pp. 5-46.

Jefferson, Gail, 1975. Error correction as an interactional resource. Language in Society 3, 181-199.

Lerner, Gene H., 1996. "Finding face" in the preference structures of talk-ininteraction. Social Psychology Quarterly 59, 303-21

Levinson, Stephen C., 1983. Pragmatics. Cambridge: Cambridge University Press.

Mazeland, Harrie, 1987. A short remark on the analysis of institutional interaction: the organization of repair in lessons. Unpublished manuscript (Published version in Dutch: Repair-organisatie in onderwijs-interakties. In: Scholtens, A. and Springorum, D. (Eds.), 1986. Gespreksanalyse. Universiteit Nijmegen: Instituut Nederlands, pp. 233-46.)

Mazeland, Harrie and Zaman-Zadeh, Minna, 2004. The logic of clarification. Some observations about word-clarification repairs in Finnish-as-a-lingua-franca interactions. In: Gardner, Rod and Wagner, Johannes (Eds.), Second Language Conversations. London: Continuum, pp. 132-156.

Pomerantz, Anita M., 1984. Pursuing a response. In: Atkinson, Paul and Heritage, John (Eds.), Structures of Social Action. Studies in Conversation Analysis. Cambridge: Cambridge University Press, pp.152-163.

Raymond, G., 2003. Grammar and social organization: Yes/no interrogatives and the structure of responding. American Sociological Review 68, 939-967

Robinson, Jeffrey D. 2006. Managing trouble responsibility and relationships during conversational repair. Communication Monographs 73/2, 137-161.

Sacks, Harvey, 1992. Lectures on conversation. 2 vols. Edited by Gail Jefferson with introductions by Emanuel A. Schegloff. Oxford: Basil Blackwell. 
Sacks, Harvey, Schegloff, Emanuel and Jefferson, Gail 1974. A simplest systematics for the organization of turn-taking for conversation. Language 50, 695-737.

Schegloff, Emanuel A., 1979. The relevance of repair to syntax-for-conversation. In:

Givon, T. (Ed.), Syntax and semantics 12: Discourse and syntax. New York:

Academic Press, 261-86

Schegloff, Emanuel A., 1987. Some sources of misunderstanding in talk-ininteraction. Linguistics 25, 201-218.

Schegloff, Emanuel A., 1990. On the organization of sequences as a source of “coherence" in talk-in-interaction. In: Dorval, B (Ed.), Conversational organization and its development. Norwood, NJ: Ablex, 51-77.

Schegloff, Emanuel A., 2007. Sequence Organization in Interaction: A Primer in Conversation Analysis 1. Cambridge: Cambridge University Press.

Schegloff, Emanuel A., Jefferson, Gail and Sacks, Harvey, 1977. The preference for self-correction in the organization of repair in conversation. Language 53, 361382.

Selting, Margret, 1987. Verständigungsprobleme. Eine empirische Analyse am Beispiel der Bürger-Verwaltungs-Kommunikation. Tübingen: Niemeyer. Selting, Margret, 1988. The role of intonation in the organization of repair and problem handling sequences in conversation. Journal of Pragmatics 12, 293322.

Sidnell, Jack, 2006. Repair. In: Verschueren, Jef and Östman, Jan-Ola (Eds.): Handbook of Pragmatics. Amsterdam: John Benjamins.

Sorjonen, Marja-Leena, 1996. On repeats and responses in Finnish conversations. In Ochs, Elinor, Schegloff, Emanuel A. and Thompson, Sandra A. (Eds.), Interaction and grammar. Cambridge: Cambridge University Press, pp. 277327.

Stivers, T. and J. Robinson, 2006. A preference for progressivity in interaction. Language in Society 35, 367-392.

Svennevig, Jan, 1999. Getting acquainted in conversation. A study of initial interactions. Amsterdam: John Benjamins.

Svennevig, Jan, 2003. Echo answers in native/non-native interaction. Pragmatics 13, 285-309.

Svennevig, Jan, 2004. Other-repetition as display of hearing, understanding and emotional stance. Discourse Studies 6, 489-516. 
